\title{
HYSTERIA AT THE EDINBURGH INFIRMARY: THE CONSTRUCTION AND TREATMENT OF A DISEASE, 1770-1800
}

by

\author{
GUENTER B. RISSE*
}

I

In the introduction to his History of sexuality, Michel Foucault pointed to the eighteenth century as the period in which sexuality became a medical concern and women were, in his words, subjected to "hysterization". ${ }^{1}$ By this term, Foucault probably meant that medicine began to pay greater attention to female bodily functions, trying to explain anew women's behaviour and physical complaints within the prevailing theoretical frameworks of the time. Thus, Foucault's seemingly novel "medicine of hysteria" replaced traditional and popular views based on humours, vapours, and the effects of a wandering womb. In his view, this was just one aspect of the medicalization imposed on eighteenth-century life with its inherent shifts in power relationships which constitutes one of the central motifs in his writings. ${ }^{2}$

The present investigation started out as an effort to organize a rich source of primary clinical material: lecture notes and patient case histories from the Royal Infirmary of Edinburgh during the late-eighteenth century. ${ }^{3}$ The analysis focused on hospitalized patients labelled as suffering from "hysteria", trying to document and perhaps clarify Foucault's ideas on the subject. Using such historical evidence, this study made some rather unexpected discoveries. It not only exposed the ambiguities inherent in the construction of disease entities, but also refuted Foucault's account of the sexualization of working-class women, at least for late-eighteenth-century Edinburgh.

Before presenting the archival data, however, it will be useful briefly to consider the views regarding women's health and especially hysteria prevalent in the medical literature during the latter part of the eighteenth century. As with other health problems, the public certainly wanted explanations from medical practitioners and demanded measures designed to ameliorate or even cure the troublesome fits. Despite

*Prof. Guenter B. Risse, MD, PhD, Department of the History and Philosophy of Health Sciences, University of California, San Francisco, California 94143-0726, USA.

${ }^{1}$ Michel Foucault, The history of sexuality, vol. 1, an introduction, trans. from the French by Robert Hurley, New York, Vintage Books, 1980, pp. 104 and 116-117. For a general overview of eighteenth-century medicine, see R. Porter, 'Medicine and the Enlightenment in eighteenth-century England', Soc. soc. Hist. Med. Bull., 1979, 29: 27-41. The social construction of disease and medicine is presented in a series of case studies: P. Wright and A. Treacher, The problem of medical knowledge, Edinburgh University Press, 1982.

${ }^{2}$ See especially Foucault's The birth of the clinic: an archaeology of medical perception, trans. from the French by A. M. Sheridan Smith, New York, Pantheon, 1973; and Madness and civilisation: a history of insanity in the age of reason, trans. from the French by R. Howard, New York, Random House, 1965.

3 The sources used for this study are a number of student case books and lecture notes. The former were from the official ward ledgers as part of the clinical instruction given to contemporary medical students enrolled at Edinburgh University. For details see Guenter B. Risse, Hospital life in Enlightenment Scotland: care and teaching at the Royal Infirmary of Edinburgh, New York and Cambridge, Cambridge University Press, 1986, especially ch. 1, pp. 7-59 and appendix A, pp. 296-302. 
a very detailed understanding of the clinical manifestations of this disease, physicians were forced to promote a rather hypothetical set of reasons that could adequately interpret as well as validate for sufferers the varied cluster of symptoms ascribed to hysteria.

Central to the professional notions about hysteria was the belief in the nervous origin of so-called "convulsive distempers", as Thomas Willis characterized them in 1667. As is well known, hysteria had already been partially detached from the traditional pathology of the uterus and reinterpreted in iatrochemical terms as the result of explosions occurring within the animal spirits as they flowed from the brain through the nerves. ${ }^{4}$

Willis's newly conceived pathophysiology of weak nerves instead of vapours made it possible to desexualize the disorder, although clinicians were quick to perceive symptomatic differences sufficient to construct a male equivalent: "hypochondriasis".

In Britain, the growing popularity of both labels and their linkage to a refined, upper-class lifestyle, touched off a veritable explosion of literature on the subject. Among the most prominent authors espousing a nerve-mediated pathology were Richard Blackmore, Nicholas Robinson, and George Cheyne. ${ }^{5}$ Most writings expounded on the deleterious effects of overeating (too much meat and gravy), excessive consumption of coffee, tea, and alcohol, and, except for too much sex, not enough physical exercise. ${ }^{6}$ At the same time, emotions such as sadness, fear, and boredom were also implicated. The net result was diffuse nerve damage affecting all bodily systems and indirectly also the mind.

The clinical course of hysteria was carefully described by Thomas Sydenham, who had repeatedly called for the establishment of "natural histories" of disease. Based on his considerable experience acquired with largely upper-class patients, Sydenham perceived hysteria to be the single most common chronic disease of his day. ${ }^{7}$ For England, at least, Foucault's "hysterization" of women seems to have been well underway by the second half of the seventeenth century.

Not suprisingly, women were considered to be more prone to such disorders of eighteenth-century civilisation because of their traditionally ascribed physical inferiority and greater susceptibility to disease. "We naturally associate the idea of female softness and delicacy with a correspondent delicacy of constitution", observed one author, John Gregory. ${ }^{8}$

\footnotetext{
${ }^{4}$ Lord Brain, 'The concept of hysteria in the time of William Harvey", Proc. R. Soc. Med., 1963,56:317-324; and John Wright, 'Hysteria and mechanical man', J. Hist. Ideas, 1980, 41: 233-247.

${ }^{5}$ For details consult Ilza Veith, 'Hysteria in England', in Hysteria, the history of a disease, University of Chicago Press, 1965, pp. 120-154; and J. M. N. Boss, 'The seventeenth-century transformation of the hysteric affection, and Sydenham's Baconian medicine', Psychol. Med., 1979, 9: 221-234.

${ }^{6}$ George Cheyne, The natural method of cureing the disease of the body and the disorders of the mind, depending on the body, London, Strahan \& Leake, 1773, pp. 52-54, as quoted in Veith, op. cit., note 5 above, p.158.

${ }^{7}$ Sydenham's ideas were expressed in his Epistolary dissertation, a lengthy discussion in the form of a letter dated 20 January 1682 and written to a colleague in Worcester, William Cole. See Thomas Sydenham, The works of Thomas Sydenham, MD, trans. from the Latin by R. G. Latham, 2 vols., London, Sydenham Society, 1850, vol. 2, pp. 85-99.

8 John Gregory, A father's legacy to his daughters, Boston, J. B. Dow, 1834, p. 32. The work was privately published in 1774 by his son James shortly after the author's death. For an explanation of contemporary
} 


\section{Hysteria at the Edinburgh Infirmary}

As one contemporary British self-help manual remarked, it was precisely this laxness of fibres or fragile texture "rendering her the most amiable object in the universe" that also subjected females to an "infinite number of maladies to which every man is an utter stranger". 9 The membranes covering all nerves were believed to be soft and thin, facilitating a strong reaction to slender impressions such as pain and sudden fear. These were the apparent physical reasons for the emotionality that characterised the female temperament.

In Scotland, the widely held concept of hysteria as a nervous disease was further articulated by Robert Whytt, a professor at the University of Edinburgh. In a work published in 1765, Whytt admitted that in a general sense all diseases affecting both sexes could be considered nervous since they resulted from alterations of the nervous system. However, the author reserved the name specifically for ailments like hysteria, which in his opinion demonstrated an "unusual delicacy or unnatural state of the nerves". 10

The rather protean symptomatology ascribed to both hysteria and hypochondriasis suggested multiple-organ involvement, and medical authors such as Whytt were quick to postulate some comprehensive "sympathy" or nerve-mediated links between the brain, stomach, intestines, and even the uterus. ${ }^{11}$ Trouble could start or end in the brain or anywhere in between. Indeed, in spite of previous efforts to de-emphasize uterine pathogenesis based on the tenets of classical humoralism, the womb was brought back into the chain of events and believed to be the initial seat of some hysteric disorders, now exercising its influence on all other bodily systems through "sympathy" and "consensus" between nerves. Association of mood swings before menstruation or instances of menstrual irregularity with other manifestations of hysteria certainly suggested a connexion. Like others before him, Whytt concluded that hysteric symptoms occurred more frequently in women whose delicate frame, lack of exercise, and menstrual troubles all conspired to predispose them to the disease. ${ }^{12}$

When William Cullen published his own disease classification in 1769 , hysteria was placed under a new class of ailments termed the neuroses. Neuroses were seen as generalized diseases caused by a malfunction of the nervous system which involved changes in sensiblity and motion. Within this class, hysteria ended up under illnesses characterized by irregular muscular contractions, the so-called spasmodic diseases, which also included tetanus, epilepsy, asthma, intestinal colics, and hydrophobia or

views, see G. S. Rousseau, 'Nerves, spirits and fibres: towards defining the origins of sensibility, with a postscript 1976', in The blue guitar, 1976, 2: 125-153.

${ }^{9}$ Anonymous, The ladies dispensatory: every woman her own physician, 2 nd ed., London, J. Hodges, 1740 , preface p. III. For an interpretation of such views as misogynist, see E. Fischer-Homberger, 'Hysterie and Misogynie - ein Aspekt der Hysteriegeschichte', Gesnerus, 1969, 26: 117-127.

10 Robert Whytt, Observations on the nature, causes, and cure of the disorders which have been commonly called nervous, hypochondriac, or hysteric, Edinburgh, T. Becket \& J.Balfour, 1765, preface, p. IV. See R. K. French, Robert Whytt, the soul and medicine, London, Wellcome Institute of the History of Medicine, 1969, Especially ch. 4, "Nervous diseases', pp. 31-45. Such "nervous" pathogenesis was not exclusively British. See, for example, Samuel A. A. D. Tissot, Traité des nerfs et de leurs maladies, 2 vols, in 4, Paris, 1778-80. For an argument that such a physiology and pathology blended with Scottish ideas and cultural values, consult C. Lawrence, 'The nervous system and society in the Scottish Enlightenment', in B. Barnes and S. Shapiro (editors), Natural order: historical studies of scientific culture, London, Sage Publications, 1979, pp. 19-40.

11 Whytt, op. cit., note 10 above, p. $\mathrm{V}$ and 28 .

12 Ibid., p. 105. 
rabies. ${ }^{13}$ Like Whytt, Cullen felt that the convulsive fits of hysteria could be linked to problems in other bodily systems, notably the "prima via" or alimentary canal. Although he refused to speculate about the precise pathways of this "sympathy", Cullen also strongly hinted that perhaps both the uterus and ovaries were involved in triggering the hysteric motions well before the appearance of gastrointestinal symptoms. The ultimate blame was bestowed on vascular plethora, and excess of blood capable of enhancing nervous irritability. ${ }^{14}$

Cullen's attempts to associate hysteria with gynaecological problems was supported by another Edinburgh professor, James Gregory. For every man affected with hysterical fits, Gregory postulated that 10,000 women suffered from such attacks. ${ }^{15}$ The basic reason for this lopsided ratio was a traditional constitutional weakness characteristic of all females, coupled with greater bodily irritability during the childbearing years. Clues for an excessive female debility were always absent or irregular menses. Instead of viewing menstrual disorders as possible effects of disease, most eighteenth-century physicians inverted the causal relationship: lack or irregular monthly flow usually foreshadowed the appearance of serious ailments, including the arrival of hysteria.

While the disease was being connected through "sympathy" with a host of other physical problems, a number of psychological factors-so called "passions of the mind" - were also said to be involved in its pathogenesis. Feelings of fear, anger, and disappointment could, according to most medical authors, easily trigger hysterical fits. Cullen even implicated sexual behaviour among the causes responsible for the disease. In fact, he mentioned a special type, the hysteria libidinosa, occurring in "those females who are liable to the nymphomania", defined as "an unrestraint desire for venereal enjoyment" based on uterine irritability. ${ }^{16}$ Other physicians wrote about the "great proclivity to venery" among hysteric females. Seductive gestures and "libidinous speeches", especially a "lascivious casting about of their eyes", were described. ${ }^{17}$ Perhaps because many hysteric women were unmarried, such explicit sexually-oriented behaviour was not viewed as morally proper and hence medicalized.

The brief survey of medical views concerning hysteria around the middle of the eighteenth century reveals a number of biases about female debility and susceptibility to disease derived from the traditional literature of previous centuries. Couched in the new language of "nerves" and "sympathies" instead of humours and vapours, these

\footnotetext{
${ }^{13}$ William Cullen, Synopsis nosologiae methodicae, Edinburgh, 1769. An English translation of this work first appeared in 1792 under the title Synopsis and nosology, Hartford, Connecticut, N. Palten, 1792. For a brief background, see W. F. Knoff, 'A history of the concept of neurosis, with a memoir of William Cullen', Amer. J. Psychiat., 1970, 127: 120-124; and Jose Lopez Piñero, Historical origins of the concept of neurosis, trans. by D. Berrios, Cambridge University Press, 1983, especially ch. 1, pp. 1-15.

${ }^{14}$ William Cullen, 'Of the hysteria or the hysteric disease', in First lines of the practice of physic, new ed., 4 vols., Edinburgh, C. Elliott, 1788, vol. 4, ch. 13, pp. 93-106. For John Brown's views on hysteria as an asthenic disease, see John Brown, The elements of medicine, trans. from Latin by the author, 2 vols., London, J. Johnson, 1795, vol. 2, pp. 230-231.

15 James Gregory, 'Hysteria', a lecture delivered to medical students in the academic year 1788-89, in MSS. Collection, National Library of Medicine, Bethesda, Maryland, p. 92. (See appendix 1.)

${ }^{16}$ Cullen, op. cit., note 14 above, vol. 4 , ch. 13 , p. 98.

${ }^{17}$ One such author was William Saunders, Elements of the practice of physic, London, 1784, p. 122; another was William Nesbit, The clinical guide, 3rd ed., Edinburgh, J. Watson, 1799, pp. 97-100.
} 
speculations dealt mostly with the psychological and physical problems of upper-class people, then the focus of most contemporary medical activities performed by professionals. Inasmuch as hysteria was widely viewed as one of the hazards of a luxurious living style that combined indolence, emotional stress, and, at times, overindulgence in food and sex, they conferred status and attention on their sufferers. So-called modern, fine ladies lost their native vigour through "unseasonable indulgence"; their minds "tortured by imaginary wants", their fragile nerves "convulsed by the insults of passion or the excesses of midnight dissipation"..$^{8}$ But how did "hysterization" occur among the poor who availed themselves of hospital care? Let us turn to the archival evidence.

II

The first set of data was obtained from surviving folios of the General Register of Patients belonging to the Royal Infirmary of Edinburgh between the years 1770 and 1800 and summarized on Tables 1 and $2 .{ }^{19}$ As can be noted, the diagnosis "hysteria" appeared rather infrequently in the registration charts except for the year 1785 , averaging only slightly over one per cent of all entries. ${ }^{20}$ Significant fluctuations from year to year in the admission of such individuals were due, perhaps, to the influx of other categories of patients for political and economic reasons. Hysteria patients were overwhelmingly female: of the 157 cases identified, 154, or ninety-eight per cent, were women.

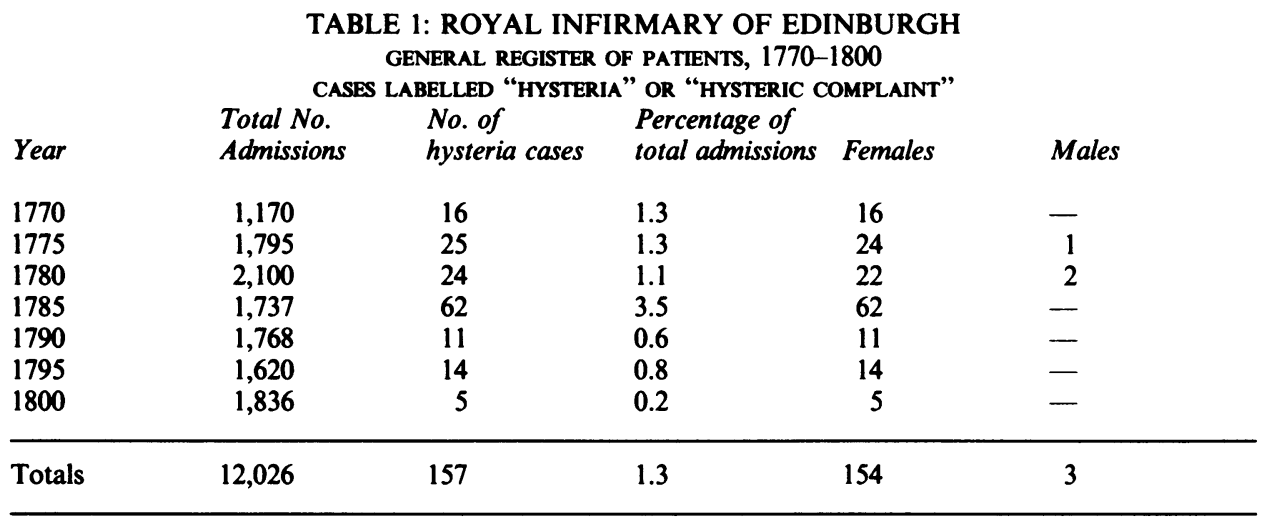

Table 2 summarizes the institutional progress of those who were accepted. More than half of the hysterics were sent to the ordinary medical ward; about one in four were listed

\footnotetext{
18 John Leake, Medical instructions towards the prevention and cure of chronic diseases peculiar to women, 5th ed., London, R. Baldwin, 1785, p. 141.

${ }^{19}$ See the surviving volumes of the General Register, available from 1770 with the exception of one folio listing patients admitted to the Infirmary between 28 March 1797 and 27 July 1799 . All volumes are preserved in the MSS. Collection, Medical Archives, University of Edinburgh. The diagnostic labels of "hysteria" and "hysteric complaint" were sorted out from all admissions listed for the year 1770, and the procedure repeated every five years $(1775,1780,1785,1790,1795,1800)$ until the end of the century. In turn, sex was determined from the patients' first names as recorded in the registers. Their destination within the Infirmary, length of hospitalization, and category of discharge were also collected. For more details, see Risse, op. cit., note 3 above, pp. 50-56.

${ }^{20}$ Acertain number of patients with hysteric complaints were entered as suffering from dyspepsia, a stomach disorder. (See appendix 2.)
} 


\section{G. B. Risse}

as servants and received into a hospital unit specifically equipped for them with the help of church donations. The rest went to the Infirmary's teaching ward where they could be observed and treated by local university professors in the presence of students. Most individuals identified as suffering from hysteria entered the hospital during the winter months, the most frequent ones being January, February, and March, in that order. Their average hospital stay was 26.5 days, slightly below the 32-day mean calculated for all medical cases, although here again considerable fluctuations occurred from year to year. $^{21}$

TABLE 2: ROYAL INFIRMARY OF EDINBURGH GENERAL REGISTER OF PATIENTS, 1770-1800 HOSPITALIZATION AND DISCHARGE OF PATIENTS WITH HYSTERIA Place of hospitalization (percentages)

\begin{tabular}{|c|c|c|c|c|c|c|c|}
\hline Year & Med. ward & $\begin{array}{l}\text { (percenta } \\
\text { Servants }\end{array}$ & Teaching & $\begin{array}{l}\text { Length of } \\
\text { hospitalization }\end{array}$ & Cured & $\begin{array}{l}\text { (percentages) } \\
\text { Relieved }\end{array}$ & "Desire" \\
\hline 1770 & 68.8 & - & 31.2 & 26.8 days & 43.7 & 25.0 & 31.2 \\
\hline 1775 & 56.0 & 12.0 & 28.0 & 45.6 & 72.0 & 24.0 & - \\
\hline 1780 & 66.6 & 29.1 & 4.1 & 22.4 & 30.0 & 45.8 & 6.4 \\
\hline 1785 & 59.6 & 35.4 & 4.8 & 21.3 & 50.0 & 40.3 & 1.6 \\
\hline 1790 & 45.4 & - & 54.5 & 36.0 & 36.3 & 45.4 & 9.0 \\
\hline 1795 & 42.8 & 50.0 & 7.1 & 17.2 & 50.0 & 42.8 & 7.1 \\
\hline 1800 & 40.0 & 20.0 & 40.0 & 20.2 & 80.0 & 20.0 & 一 \\
\hline Average & 57.9 & 25.4 & 15.9 & 26.5 days & 49.6 & 36.9 & 7.6 \\
\hline
\end{tabular}

Finally, less than half of all hysteria patients were considered "cured" at the time of their discharge, perhaps a significant reflection of the somewhat intractable character of the disease as well as lack of effective treatment. One must remember that the official statistics list an average cure rate of over seventy per cent for all hospitalized individuals. More than a third were listed as leaving the hospital "relieved", a somewhat ambiguous term that generally meant temporary improvement but possible chronicity. This figure represents a threefold increase over the published totals. A third category, "dismissed by desire", referred to hospitalized patients who requested their own discharge, mostly because they had become disillusioned or displeased with the results of their treatment. Here, too, those labelled as "hysterics" left in greater numbers, accounting for more than seven per cent of all dismissals, while the average for the hospital was five per cent. Not a single fatality was reported among hospitalized cases of hysteria. ${ }^{22}$

The second, and by far more important source of information was fourteen student case books, each containing between fifty and seventy complete clinical histories directly copied from the Infirmary's official ward journals. ${ }^{23}$ As can be seen from

${ }^{21}$ For more information about hospitalization at the Edinburgh Infirmary, consult Risse, op. cit., note 3 above, especially ch. 2, 'Hospital staff and the admission of patients', pp. 60-118.

22 The published statistics of admissions and discharges indicate that the Edinburgh Infirmary reported a steady overall cure rate of seventy per cent, with about ten per cent listed as "relieved", an indication that patients suffering from hysteria did not fare too well in an institutional setting. These hospital statistics were usually published in the January issue of Scots Magazine, a popular contemporary monthly covering political, social, and literary events.

${ }^{23}$ The case books cover chronologically almost three decades of hospital practice. All the patients listed in the individual notebooks were admitted to the hospital's teaching ward and presented by the attending professors to students during lectures and rounds. Since the students copying the cases have remained 
Table 3, the case books reveal the presence of thirty hysteric patients in the teaching ward between the years 1771 and 1799-all women-representing a much higher percentage among entering patients than the contingent admitted to the Infirmary as a whole.

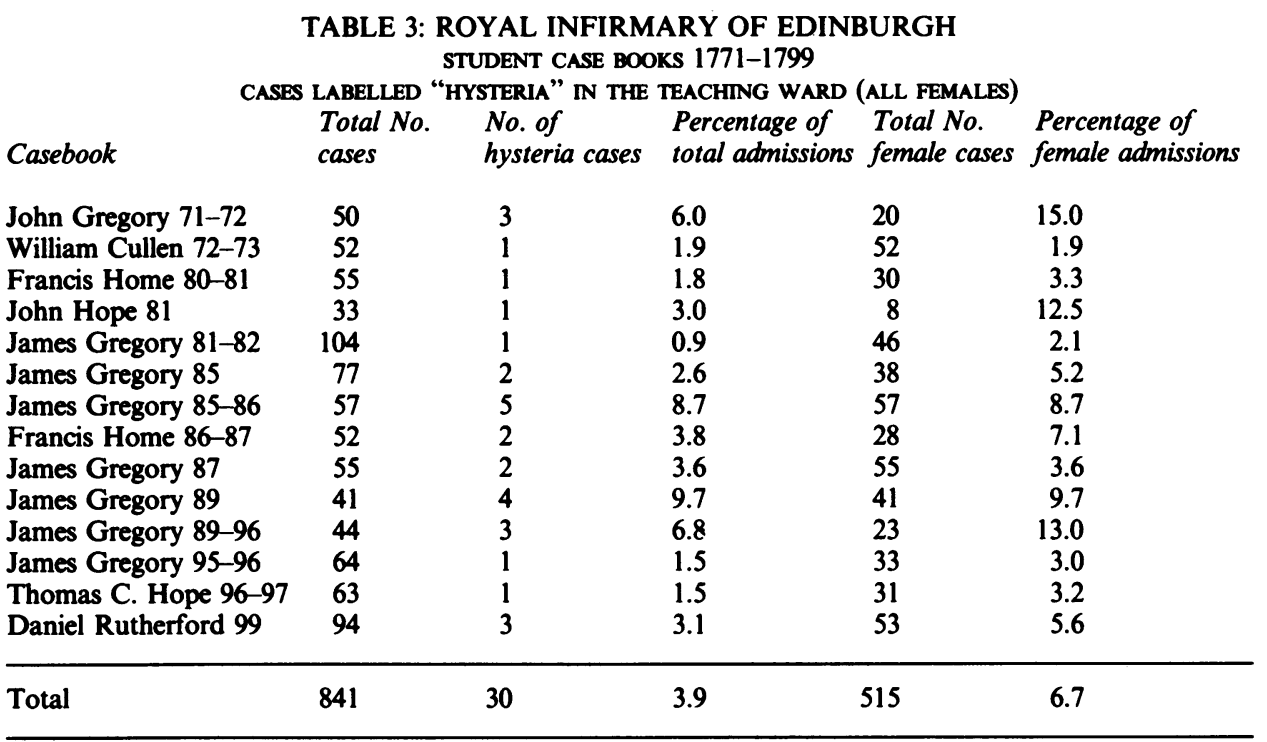

Among the reasons given for the low hospital admission rates was the threat of a disciplinary breakdown in the institution if too many hysterics were accepted. Indeed, attending physicians were reluctant to accept any hysteric women into the wards because their frequent fits proved contagious, triggering similar attacks of disruptive behaviour among other hospitalized patients suffering from different ailments. "I wish to take in as few hysteric patients as possible", remarked James Gregory in 1788, "as I believe more have been seized with this disease in the hospital than have [been] cured [of] it." 24 In fact, Gregory claimed that on one occasion he had to contend with six women, all of them seized with fits during the same night, undoubtedly creating an uproar in the small teaching ward, usually without nurses during the night shift. ${ }^{25}$

Another reason for the restricted admission of patients believed to suffer from hysteria was the widespread recognition that the hospital environment usually conspired against a cure. Lack of fresh air in the wards, inactivity, and few opportunities for "employment of mind" could certainly aggravate the psychological factors contributing to the disease. ${ }^{26}$

anonymous, the notebooks are listed by the name of the professor in charge of the ward during that specific rotation. For more information, consult Risse, op. cit., note 3 above, especially ch. 5, 'Clinical instruction', pp. 240-278, and appendix A, pp. 296-301. A complete case of hysteria from James Gregory's rotation in the year 1781-82 is reproduced in appendix B, pp. 336-339.

${ }_{24}^{4}$ Gregory, op. cit., note 15 above, p. 86 .

${ }^{25}$ Ibid., p. 86; Whytt, op. cit., note 10 above, p. 215. Similar instances of this imitative behaviour - still today referred to as "hysterical contagion" - were reported in eighteenth-century church assemblies and theatrical performances.

${ }^{26}$ Ibid., p. 86. Similar comments were made by Gregory in discussing the case of Isabel Gray, a twenty-four-year-old unmarried patient, in James Gregory, Clinical cases of Dr. Gregory in the Royal 
Given the recurrence of malingering patients trying to gain access to the Edinburgh Infirmary, especially during the winter months, the vague complaints suggestive of hysteria were often viewed with suspicion. In fact, one fifteen-year-old female servant admitted by Francis Home in January 1787 was said to be "full of imaginary [hysteric] complaints" and quickly released. ${ }^{27}$ William Cullen, who was quite concerned about the honesty of all hospital patients and used nurses to confirm or disprove complaints, confided that in one particular case "I had never been attentive to the hysterical symptoms", adding that "we had some accounts of them on our first visit but for many reasons I never trust to the fits reports and therefore when they [fits] appeared, I considered it a very accidental affair but with two more fits occurring, [they] engaged my attention."28 James Gregory, for his part, suggested that some hysterical fits were deliberately induced by the patients. Lecturing to students, Gregory declared that "there is a peculiar pleasure that attends the coming of the fit analogous, I suppose, to that we experience in yawning, and that they [patients] really encourage them and bring them on by reason of every possible effort." 29

Finally, the teaching staff accepted a fair number of hysteric patients for purely didactic reasons. As James Gregory explained, so "that we may see it in its different shapes" and because of the challenges to clinical management. Indeed, Gregory believed that each year hysteria presented itself in new guises that were "apt to deceive the young practitioner". To avoid deceit and diagnostic confusion, students needed to see hysteric patients and were instructed to learn the distinctions between hysteric and epileptic fits. ${ }^{30}$

In spite of such threats to institutional discipline and purpose, Infirmary physicians considered hysteria a "proper" disease for hospital care and they admitted a small number of individuals apparently afflicted by this disease to the teaching ward. As the patient profile indicates, the average age of hysterics was $23 \frac{1}{2}$, slightly below the mean calculated for all other women hospitalized in the teaching ward. The youngest patient was fourteen, the oldest sixty-two, thus considerably beyond the childbearing age postulated as typical for the appearance of hysterical complaints. ${ }^{31}$ Some of these labouring-class women probably came to the Infirmary of their own accord or were brought in by relatives. Perhaps they were concerned and even frightened by the symptoms they were experiencing, especially the sensations of suffocation and blackouts. Others, with recurrent gastrointestinal complaints or menstrual irregularities, may have been worried about their digestion or childbearing potential, if one can believe their clinical histories. ${ }^{32}$

Infirmary of Edinburgh, taken by Nathan Thomas, Edinburgh 1785-86, MSS. Collection, University of Edinburgh. (See complete case in appendix 2.)

${ }^{27}$ Case of Janet Nisbet, a fifteen-year-old unmarried servant, in Francis Home, Cases of patients under the care of Francis Home, Edinburgh, 1780-81, MSS. Collection, Royal College of Physicians, Edinburgh.

${ }^{28}$ William Cullen, Clinical lectures delivered for John Gregory, February-April 1772, Edinburgh 1772, MSS. Collection, Royal College of Physicians, Edinburgh.

${ }^{29}$ Gregory, op. cit., note 15 above, p. 98 .

${ }^{30}$ Case of Isabel Gray, in James Gregory, op. cit., note 26 above. (See appendix 2.)

31 Of those women listing their marital status - about half - sixty-three per cent were unmarried while the rest were about equally divided between married and widowed females.

32 In fact, among all women listed in student case books, nearly two-thirds provided information about their menstrual periods. It is noteworthy that nearly eighty per cent of the respondents acknowledged suffering 


\section{Hysteria at the Edinburgh Infirmary}

The frequency of servants among the those recorded as hysterics both in the General Register and the student case books suggests that Edinburgh employers possibly took advantage of the nosological label and the existence of a Servants' Ward in the Infirmary to rid themselves of troublesome domestic helpers and thereby avoid further obligations. Since the average duration of symptoms ascribed to the disease was about five months, hysteria was certainly a chronic and recurrent problem that must have created a number of interpersonal conflicts while duties and obligations went unheeded.

As in previous centuries, the symptomatology associated with hysteria was thought to be quite protean, often beginning with the so-called clavus hystericus, a sensation of sharp pain in the head as if a nail had been driven through it. At other times, the affected individual first reported grumbling noises in the belly, followed by a sensation of balls moving across the lower abdomen and then heading upwards toward the stomach. ${ }^{33}$ After much twisting, cramping, and belching in the pit of the stomach, the imaginary balls gradually ascended along the oesophagus, producing a sensation not unlike "the creeping of an animal on its hind legs". ${ }^{34}$ This movement was accompanied by a frequent pulse, precordial oppression, difficult breathing (asphyxia hysterica), trouble swallowing (dysphagia hysterica), and finally, a sense of suffocation as the fictional balls or "globus" reached the throat.

The pathognomonic sign appeared when the patient, in the language of the times, "took to the fits". The actual attack was often a set of violent motions during which the patient laughed or wept. One patient in the casebooks was described as striking and kicking herself as well as those around her before falling to the ground and remaining there, apparently unconscious, for variable periods of time. ${ }^{35}$ Paroxysms fluctuated from fifteen- to twenty-minute episodes, perhaps repeated three or four times daily, to one-hour spells with the patient foaming from the mouth just as in epileptic seizures. The violent motions were at times replaced with generalized muscular contractions accompanied by great rigidity, thus creating bizarre arched postures. ${ }^{36}$ Simple swooning or fainting spells were also considered valid substitutes for hysteric fits. Others, in turn, just complained of seeing "floaters" before their eyes or possessed a "dimmed" eyesight. Following the attacks, patients seemingly recovered their senses quickly, voided large amounts of clear urine, or displayed residual muscular twitches and speech difficulties for brief periods of time.

From the Edinburgh casebooks it seems obvious that only a minority of females labelled as suffering from hysteria actually displayed the characteristic fits. A majority simply complained of a loss of appetite, burning in the stomach, intestinal cramps,

\footnotetext{
from amenorrhoea at the time of admission. This issue is more fully discussed in G. B. Risse, 'Gynecological disorders in eighteenth-century hospital practice' (forthcoming).

${ }^{33}$ For an overview of the symptomatology, consult 'Hysteria' in The Edinburgh practice of physic, surgery, and midwifery, new ed., 5 vols., London, G. Kearsley, 1803, vol. 2, pp. 439-440.

${ }^{34}$ This description was given in the case of Betty Drysdale, a fifteen-year-old girl, in James Gregory, Clinical cases of patients in the Royal Infirmary of Edinburgh, Edinburgh, 1787, MSS. Collection, National Library of Medicine, Bethesda, Maryland.

${ }^{35}$ Case of Elizabeth Miller, in John Gregory, Clinical cases of the Royal Infirmary of Edinburgh, 1771-72, MSS. Collection, Medical Archives, University of Edinburgh.

${ }^{36}$ Case of Cecilia McLean, in James Gregory, op. cit., note 26 above.
} 


\section{G. B. Risse}

menstrual difficulties or irregularities, headaches, fainting spells, and other nonspecific symptoms. In two cases seen in 1799 by another Edinburgh professor, Daniel Rutherford, the women complained of uneasiness and suffocation, symptoms that were eventually recognized as belonging to chronic chest ailments. In one instance, the lungs were affected, while the other one turned out to be an inflammation of the breast. ${ }^{37}$ One of James Gregory's patients "was affected with the most astonishing cough I have ever observed, continuing for two days without a second of intermission." 38 Interestingly enough, some of the actual attacks occurred solely in response to the therapeutic measures instituted to control the disease. One of John Gregory's charges, for example, was "seized with a fit when the blood was flowing from her arm" following a venesection. ${ }^{39}$ Others reacted negatively to the application of blisters and administration of evil-tasting draughts prescribed by the consulting physician.

What was the plan of treatment? In accordance with eighteenth-century notions that hysteria was a disease of weakened nerves, a stimulating regimen was usually recommended to prop up the debilitated constitution. ${ }^{40}$ The therapeutic regimen called for the manipulation of the so-called non-naturals, including the provision of a simple but nourishing diet that excluded tea and coffee. Alcohol was banned except for a few glasses of red wine diluted with water before dinner, considered a standard component of all envigorating plans.

In addition, patients were told to increase their physical activities by taking walks in the yard of the hospital, or using a set of dumb-bells. One of James Gregory's patients was ordered to exercise daily on a wooden bench equipped with a spring mechanism otherwise referred to as the "exercise machine" or "spring deal". ${ }^{41}$ For others, a wooden horse was available to provide the salutary effects ascribed to horseback riding, a practice routinely recommended to patients of means. At the same time, hospitalized individuals were instructed to put their minds at ease and leave their worries behind. "The mind ought to be diverted and kept easy and cheerful as possible", wrote Whytt, adding that "nothing hurts more the nervous system and particularly the concoctive powers than fear, grief, and anxiety." 42

The strictly medical programme was individually tailored to address the most bothersome complaints, particularly the hysteric fits so disruptive to hospital routine. Opium, usually administered in the form of laudanum, was the drug of choice, "peculiarly useful", according to Whytt, "when symptoms are owing to an extraordinary delicacy of the nervous system." $" 43$ Musk and camphor preparations were also employed. Frequent side-effects of opiate ingestion were constipation and

\footnotetext{
${ }^{37}$ Cases of Margaret Paterson and Mary Taylor in Daniel Rutherford, Clinical cases, Edinburgh, 1799, MSS. Collection, Royal College of Physicians, Edinburgh.

${ }^{38}$ Gregroy, op. cit., note 15 above, p. 89.

39 Case of Helen Thykston, in John Gregory, op. cit., note 35 above.

${ }^{40}$ Edinburgh practice of physic, op. cit., note 33 above, pp. 441-442. See also Bartholomew Parr, 'Hysteria', in The London medical dictionary, rev. ed., 2 vols., Philadelphia, Mitchell, Ames, \& White, 1819, vol. 1, pp. 784-785.

${ }^{41}$ Case of Renny Mathew, in James Gregory, Cases of patients under the care of James Gregory, MD, Edinburgh, 1781-82, MSS. Collection, Royal College of Physicians, Edinburgh.

${ }^{42}$ Whytt, op. cit., note 10 above, p. 358.

${ }^{43}$ Ibid., p. 360.
} 
increased tolerance. Since the gastrointestinal troubles were often thought to be at the root of the problem, traditional bowel-cleaning procedures believed to unburden the body of potentially harmful wastes were initiated through the use of purgatives and emetics.

Another group of so-called antispasmodic drugs were also administered to hysteria patients. Some of them were draughts containing ether or consisted in the inhalation of asafoetida, a resin endowed with an obnoxious odour. The same principle of irritating the nose to help individuals recover consciousness prompted the use of tobacco fumes or burnt feathers. These preparations, designed to overcome or prevent the fits, were supplemented by the administration of tonic remedies to strengthen the nerves and bodily constitution, including bitters, Peruvian bark, and steel shavings. ${ }^{44}$

Popular among the physical methods prescribed in hysteria were blisters, the practice of producing superficial sores on specific areas of the skin (see Table 4). Originally designed to remove harmful humours from the body, this traditional method was now reinterpreted according to the new tenets of neurophysiology. Thus, blisters were seen as general stimulants because of their irritating qualities. ${ }^{45} \mathrm{At}$ Edinburgh, blistering consisted in the local application of mustard flour, garlic, or diluted sulphuric acid with the help of a dressing. Preferred sites for blistering were the nape of the neck, the shaved crown of the head, and occasionally the back between the shoulder blades. These bandaged sites usually "answered" within twelve to twentyfour hours by "rising" and forming vesicles that were then periodically pierced to drain their fluid.

\section{TABLE 4: ROYAL INFIRMARY OF EDINBURGH} STUDENT CASEBOOKS 1771-1799

DRUGS AND PHYSICAL METHODS EMPLOYED IN THE TREATMENT OF HYSTERIA

$\begin{array}{llll} & \begin{array}{l}\text { Overall } \\ \text { frequency }\end{array} & \begin{array}{l}\text { James Gregory's } \\ \text { casebooks }\end{array} & \begin{array}{l}\text { Other } \\ \text { casebooks }\end{array} \\ \text { Anodynes or analgesics } & 50.0 \% & 60.6 \% & 33.3 \% \\ \text { Purgatives } & 45.8 & 33.3 & 58.3 \\ \text { Blisters } & 41.6 & 41.6 & 41.6 \\ \text { Antispasmodics } & 29.1 & 25.0 & 33.3 \\ \text { Electric sparks } & 25.0 & 50.0 & - \\ \text { Emetics } & 20.8 & 8.3 & 33.3 \\ \text { Footbaths } & 20.8 & 16.6 & 33.0 \\ \text { Bloodletting } & 16.6 & - & 25.0 \\ \text { Fomentations } & 16.6 & 8.3 & 16.6 \\ \text { Leeches } & 12.5 & 8.3 & \end{array}$

Another fairly frequent treatment for hysteria was electricity. Within the new medicine of nerves, electricity was also viewed as a powerful stimulant and as early as 1750 the Edinburgh Infirmary acquired its first static electrical apparatus. ${ }^{46}$ Most individuals were subjected to the method of "drawing sparks", as contact was made with the patient sitting on a chair. Touching the skin with wooden or metal points

\footnotetext{
${ }^{44}$ Parr, op. cit., note 40 above, vol. 1, p. 785; Gregory, op. cit., note 15 above, pp. 103-105.

${ }^{45}$ For an overview, see Risse, op. cit., note 3 above, pp. 210-211; Parr, 'Blisters', in op. cit., note 40 above, vol. 1, pp. 254-256.

${ }^{46}$ Royal Infirmary of Edinburgh, Minute books, vol. 3, meeting of 20 April 1750, p. 53.
} 
connected to chain conductors allowed for localized sparks, directed at specific regions of the body, especially the throat, seat of the suffocating "globus". Those patients simultaneously suffering from amenorrhoea usually received on a daily basis some moderate electrical shocks over the lower abdomen. The electrical procedures were administered by the surgical clerk and occasionally reported to be painful. Not surprisingly, physicians remained divided about the usefulness of these treatments in hysteria. ${ }^{47}$

As in other gynaecological conditions, practitioners tried very hard to restore the menses through the use of warm water and thus diminish the hypothetical uterine irritability. A bath was believed to exert an important relaxing effect on a variety of spasmodic ailments, including hysteria. Given the institutional difficulties associated with the provision of hot water, physicians compromised and merely ordered a footbath, or pediluvium, requiring a minimum of staff assistance. Here it was hoped that the beneficial effects would diffuse from the feet to the rest of the body. ${ }^{48}$

Other substitutes were the fomentation of the abdomen and legs, especially at bedtime, carried out by nurses. Two flannel cloths dipped in hot water were alternately placed on the skin and left there until the warming effect wore off. The entire operation usually lasted about half an hour and could be repeated one or two times daily. By contrast, a cold bath was occasionally ordered to stimulate the entire body if a marked constitutional debility was suspected as the underlying reason for hysterical complaints. Not surprisingly, patients were not always eager to submit to these baths, particularly during the winter months. Hospital practitioners, therefore, compromised and simply immersed the patients' hands in cold water. Hysteric fits were also stopped by the shock of throwing cold water on the patient's face. "Recurrence of a paroxysm stopped speedily by a pitcher of water", read one progress note of a 1797 case under the care of another Edinburgh professor, Thomas C. Hope. ${ }^{49}$ The patient was a nineteen-year-old servant with almost daily hysteric attacks. Sometimes just the threat would do. "Fit stopped by threat of cold bath", stated on report concerning a patient of John Gregory hospitalized during November $1785 .^{50}$

A final observation about bloodletting. Two patients listed in the case books were bled during their hospital stay because of what was perceived to be their florid complexion and sanguine temperament. Venesections ordered by John Gregory amounted to a total of twenty-eight ounces in one patient, successively withdrawn over a period of nearly forty days from December 1771 to January $1772 .{ }^{51}$ The other woman, under the care of Francis Home, merely lost eight ounces as part of her initial treatment. ${ }^{52}$ Two other individuals had leeches applied to their temples for persistent headaches.

\footnotetext{
${ }^{47}$ Risse, op. cit., note 3 above, pp. 213-217; William Cullen, 'On electricity as applied to medicine', in Clinical lectures delivered in the years 1765 and 1766, London, Lee \& Hurst, 1797, p.243.

${ }^{48}$ Gregory, op. cit., note 15 above, pp. 98-100; see also William Cullen, Clinical lectures, Edinburgh 1772-1773, MSS. Collection, Royal College of Physicians, Edinburgh.

${ }^{49}$ Case of Helen Christie, in Thomas C. Hope, Clinical casebook, Edinburgh, 1796-1797, MSS. Collection, Royal College of Physicians, Edinburgh.

${ }^{50}$ Case of Isabel Gray, in James Gregory, op. cit., note 26 above.

${ }^{51}$ Case of Helen Thykston, in John Gregory, op. cit., note 35 above.

52 Case of Lilly Thomson, in Francis Home, op. cit., note 27 above.
} 


\section{Hysteria at the Edinburgh Infirmary}

Such restraint may seem remarkable given the contemporary views about vascular plethora as a possible cause of nervous irritability, especially if lodged in the reproductive organs. Indeed, in another case presented during clinical lectures, William Cullen advocated bleeding a particular hysteric patient three or four ounces every day until the fits abated. After more than twenty ounces had been removed without results, Cullen finally admitted that "I am doubtful how far we go on in this practice". 53 In general, bloodletting was perceived to be an ineffective remedy in hysteria since in eighteenth-century terms it tended to weaken patients whose entire symptomatology was already thought to be caused by debility. The exceptions were individuals with ruddy complexions which suggested bodily constitutions hardy enough to withstand the bleedings.

As expected, most treatments were deemed successful by the practitioners who prescribed them, either because the fits temporarily subsided while the patient remained hospitalized, or the complaints of suffocation or "globus" in the throat simply ceased to be reported. James Gregory seems to have often relied on the power of suggestion to prevent subsequent recurrences. "It is a maxim I inculcate very strongly to my patients", observed Gregory, "to use their utmost endeavours to prevent the coming of the fits. I have often known it to succeed though my advice is not well received by many." 54 However, most menstrual irregularities, especially the amenorrhoeas, remained unchanged.

TABLE 5: ROYAL INFIRMARY OF EDINBURGH STUDENT CASEBOOKS 1771-1799

HYSTERIA-A PATIENT PROFILE

\begin{tabular}{|c|c|c|c|c|c|}
\hline Average age & Marital status & $\begin{array}{l}\text { Reporting } \\
\text { Menstrual hx }\end{array}$ & $\begin{array}{l}\text { Duration of } S X \\
\text { prior to admission }\end{array}$ & $\begin{array}{l}\text { Average } \\
\text { hospitalization }\end{array}$ & $\begin{array}{l}\text { Cure } \\
\text { rate }\end{array}$ \\
\hline 23.5 years & $63 \%$ unmarried & $\begin{array}{l}81 \% \text { suffering } \\
\text { from menstrual } \\
\text { irregularities or } \\
\text { amenorrhoea }\end{array}$ & 19 weeks & 23.2 days & $54.1 \%$ \\
\hline \multicolumn{2}{|c|}{ JAMES GREGORY'S HYSTERIA PATIENTS (PROFILE) } & $\begin{array}{l}\text { GORY'S HYSTERIA } \\
\text { Menstrual hx }\end{array}$ & $\begin{array}{l}\text { PATIENTS (PROFILE) } \\
\text { Duration of } S X \\
\text { prior to admission }\end{array}$ & $\begin{array}{l}\text { Average } \\
\text { hospitalization }\end{array}$ & $\begin{array}{l}\text { Cure } \\
\text { rate }\end{array}$ \\
\hline 24.5 years & $50 \%$ unmarried & $\begin{array}{l}72.7 \% \\
\text { suffering from } \\
\text { irregularities }\end{array}$ & 29 weeks & 13.0 days & $33.3 \%$ \\
\hline Average age & Marital status & $\begin{array}{l}\text { DISEASES AFFECT } \\
\text { Menstrual } h x\end{array}$ & $\begin{array}{l}\text { ING FEMALES } \\
\text { Duration of } S X \\
\text { prior to admission }\end{array}$ & $\begin{array}{l}\text { Average } \\
\text { hospitalization }\end{array}$ & $\begin{array}{l}\text { Cure } \\
\text { rate }\end{array}$ \\
\hline 25.5 years & $48 \%$ unmarried & $\begin{array}{l}60.4 \% \\
\text { suffering from } \\
\text { irregularities }\end{array}$ & 9.6 weeks & 26.1 days & $59.2 \%$ \\
\hline
\end{tabular}

${ }^{53}$ Cullen, op. cit., note 28 above, p. 191.

54 Gregory, op. cit., note 15 above, p. 97. 


\section{G. B. Risse}

In the teaching ward, the average hospital stay of these hysteric patients was slightly over three weeks, below the mean established for all females admitted to that unit (see Table 5). James Gregory, for his part, kept his patients less than two weeks, but such a shorter period of hospitalization did not necessarily reflect a greater ability or success in treating the disease. In the eyes of Edinburgh practitioners the long-term prognosis of hysteria always remained guarded since the problem was considered chronic due to the inherent constitutional weakness of most females and the fragility of their nervous systems. In fact, as Whytt remarked, "it is frequently beyond the art to eradicate the disorders we now treat of."55

Although well below the average rankings published by the Edinburgh Infirmary, the fifty per cent cure rate for hysteria is somewhat deceptive since most of these patients experienced only temporary relief from some of their manifold symptoms. There is evidence that some of them were subsequently readmitted to the hospital with similar complaints. Over the years James Gregory's patients fared even worse, with only a third of them discharged as "cured", fifty-eight per cent "relieved", and eight per cent dismissed "by desire". A comment made by James Gregory in connexion with a case of amenorrhoea also applies to hysteria and illustrates the linkage of female health to sex life within marriage. At the time of discharging the patient, Gregory explained that "after exhausting my artillery, I sent her out to her husband who I thought might do more for her than I could." 56 Again, as in the General Register, no fatalities were reported among all the hysteric patients disclosed in student casebooks (see Table 6).

\begin{tabular}{lccc} 
Casebook & Cured & \multicolumn{2}{c}{ Discharge percentages } \\
& & & Relieved \\
John Gregory 71-72 & 33.3 & - & 66.6 \\
William Cullen 72-73 & 100.0 & - & - \\
Francis Home 80-81 & 100.0 & - & - \\
John Hope 81 & 100.0 & - & - \\
James Gregory 81-82 & 100.0 & - & - \\
James Gregory 85 & 50.0 & 50.0 & - \\
James Gregory 85-86 & 60.0 & 40.0 & - \\
Francis Home 86-87 & 100.0 & - & 25.0 \\
James Gregory 87 & - & 100.0 & 33.3 \\
James Gregory 89 & - & 65.0 & - \\
James Gregory 89-96 & - & 100.0 & - \\
James Gregory 95-96 & - & - & - \\
Thomas C. Hope 96-97 & 100.0 & 33.3 & $8.9 \%$ \\
Daniel Rutherford 99 & 66.6 & $33.3 \%$ & \\
\hline Total averages & $57.8 \%$ & &
\end{tabular}

${ }^{55}$ Whytt, op. cit., note 10 above, p. 332.

${ }^{56}$ Case of Euphemia McKay, in James Gregory, op. cit., note 26 above. 
III

What kind of conclusions can one reach from these hospital records? What do they tell us about hysteria that is new or different? As mentioned before, Foucault's statement that labouring women managed to escape hysterization for a long time is not borne out by the information collected from both Edinburgh registration records and students case books. ${ }^{57}$ With the arrival of lower-class persons in dispensaries and hospital wards, physicians were compelled to expand the causal relationships previously established for private patients between a luxurious and indolent lifestyle and the appearance of hysteria. Imitating the rich in their frequent consumption of tea and coffee, or drinking spirits in excess, could certainly ruin anybody's stomach, regardless of class and gender. ${ }^{58}$ As one medical author remarked, servants through "continual intercourse with people of decent manners" acquired a "delicacy of body and sensibility of mind" similar to that displayed by their employers. ${ }^{59}$ More importantly, flatulence and bowel cramps could be the result not of over-indulgence, but of a meagre diet of oatmeal, barley, cabbage, and potatoes frequent among common folk. ${ }^{60}$ Finally, frequent exposure to cold and moisture, especially near the time of menstruation, could lead to further irritations of the uterus and hence hysteric symptoms. ${ }^{61}$

At the same time, emotional factors implicated in the causality of hysteria had no monopoly on rich people either. A number of cases in the student notebooks mention anxiety and "depression of spirits", or "shock from sudden death of husband". 62 Sexual excess or repression, in turn, could also occur across social classes and be a factor in the appearance of hysteria, based on the widely held concept that a proper "stimulus of love" guaranteed normal menstrual functions. ${ }^{63}$

Physicians' ignorance about the causes and bodily processes of hysteria is not surprising given their lack of understanding of female sexual physiology. A vague morbidity of lax fibres, weak nerves, and irritable wombs interpreted and authenticated the multiple events surrounding the disease. Moreover, its low mortality foiled the execution of post-mortem examinations which could possibly have yielded important knowledge concerning other pathological conditions. However, such medical explanations were perhaps therapeutical to the patients receiving them,

\footnotetext{
${ }^{57}$ Foucault, op. cit., note 1 above, p. 121.

58 William Buchan, Domestic medicine or a treatise on the prevention and cure of diseases by regimen and simple medicines, enl. ed., New York, R. Scott, 1812, p. 62. For further details, see C. Lawrence, 'William Buchan: medicine laid open', Med. Hist., 1983, 57: 22-42; and R. Porter, 'Lay medical knowledge in the eighteenth century: the evidence of the Gentleman's Magazine', ibid., 1985, 29: 138-168.

${ }_{59} \mathrm{John} \mathrm{C}$. Lettsom, On the improvement of medicine in London on the basis of public good, 2nd ed., London, J. Phillips, 1775, p. 28.

${ }^{60}$ Whytt, op. cit., note 10 above, p. 414.

${ }^{61}$ Cullen, op. cit., note 14 above, vol. 4 , ch. 13, pp. 97-98.

${ }^{62}$ See case of Janet Nisbet, in Francis Home, op. cit., note 27 above; as well as the cases of Elizabeth Miller ("sudden death of husband") and Peggy Thomson ("scoldings from a young woman") in John Gregory, op. cit., note 35 above.

${ }^{63}$ Cullen spoke hopefully about the favourable effects derived from the "exercise of venery" (op. cit., note 14 above, vol. 3, p. 41). Another author suggested: "Follow Hippocrates: a woman's best remedy is to marry and bear children", John Bull, The female physician; or every woman her own doctress, London, L. Davis, 1770 , p. 15.
} 


\section{G. B. Risse}

especially if they came from well-known authors and teachers of international reputation such as Whytt, Cullen, and the Gregories, all attending at the Edinburgh infirmary.

At the theoretical level, both ambiguously defined entities "hysteria" and "hypochondriasis" solidified their place among the disorders of the nervous system, especially through inclusion among the neuroses of Cullen's nosology. In spite of such a reclassification, contemporary medical authors persisted in linking the nervous manifestations of hysteria to other functional changes occurring in the womb. Placing the blame for hysteria on fragile nerves and the weak bodily constitutions allowed physicians to redefine the traditional views about the physical inferiority of women.

Moreover, practitioners frequently continued to associate the manifestations of hysteria with menstrual irregularities, further highlighting the hypothetical female fragility and propensity to disease. Perhaps such a relationship was derived from or supported by the clinical evidence. From the patient registers and student case books, it appears that a majority of cases labelled "hysteria" at the Edinburgh Infirmary were admitted during the winter months. In part, this was due to the academic schedulingthe teaching ward was in use only from November to April. Since menstruation, as Cullen observed, virtually ceased among the labouring women during the winter, only to return with "the advancing warmth of spring", a significant number of women coming into the hospital admitted to such an amenorrhoea. ${ }^{64}$ The condition was perhaps an effect of widespread malnutrition.

It seems clear that the eighteenth-century construction of hysteria covered a wide variety of symptoms and ailments. The sometimes baffling symptomatology of hysteria, from headaches to fainting spells, stomach upsets to asphyxiating "globus", abdominal cramps to seizures, was thus neatly acccounted for through "sympathy" between major organ systems and a "consensus" within the framework of nerves. From epilepsy to migraine headaches, hyperventilation to stomach ulcers, bowel problems to gynaecological conditions, all could be included under the label "hysteria".

In that sense, hysteria can be said to have undergone considerable expansion within the context of eighteenth-century neurophysiological views of disease. For better or worse, patients' complaints were given a hearing and a diagnostic label. This was followed by a regimen designed to strengthen their lax bodies and relax their worried minds. Persons "liable to globus" or suffering from "hysteric complaints" were told that their weak constitution, unhealthy lifestyle, or both, were at fault. Given the chronic nature of the complaints and the transient accomplishments of medical treatment, the key to success was prophylaxis.

Hence, eighteenth-century physicians issued a series of dietary and behavioural recommendations for rich and poor women alike, a blueprint for matrimonial living that tended to justify and support the prevailing social and biological notions of womanhood. With the help of textbooks and popular manuals written by a number of medical authorities, these prescriptions were widely disseminated and even accepted by women themselves, regardless of social position and income. ${ }^{65}$ At best, the rules provided confidence that a careful plan of behaviour would be rewarded with health or

64 Cullen, op. cit., note 28 above, p. 8.

${ }^{65}$ Buchan, op. cit., note 58 above, pp. $270-271$. 
stop the recurrence of hysteric episodes. At worst, these prescriptions served to stress personal responsibility in the genesis of hysteria and frustrate those women who found it impossible to comply.

According to the conventional medical wisdom, hysteria was a chronic, quintessentially feminine, disease resulting from the peculiar constitution and physiology of women. Accordingly, symptoms were triggered when females failed to follow detailed prescriptions for a lifestyle that shunned all excesses and allowed for a limited expression of sexuality within marriage, consonant with prevailing mores and social roles. Transgressions, real or surmised, could create "liability to globus". In the eyes of eighteenth-century practitioners, women afflicted by hysteria had only themselves to blame for not paying enough attention to the advice of experts. From this professional perspective, at least, "hysterization" was a just punishment for non-conforming females who dared weaken their already fragile nerves or flaunted their sexuality.

Authors writing about hysteria during the nineteenth century have considered its manifestations as part of a socially acceptable pattern of behaviour that expressed both consciously and unconsciously those psychological frustrations directly linked to the restricted role of women in society. ${ }^{66}$ Whether this similarly applies to the lateeighteenth century remains to be studied. Throughout the ages, psychological stress, whatever its origin, followed by hyperventilation and its physiological effects, has certainly accounted for a number of the bodily manifestations of the disease. However, as a recent author writing on hysteria remarked, "we are dealing with a disorder of infinite variety determined always by human motives and circumstances" ${ }^{67}$ Since such reasons and conditions change a great deal, it is difficult to compare hysteria across time and within different cultural settings. Its virtual disappearance in advanced technological societies suggests that perhaps modern women have developed other coping mechanisms.

In any case, the eighteenth-century reality, as expressed in student case books and clinical lectures given at the Edinburgh Infirmary, was quite different. Women admitted to the hospital failed to conform to the stereotype of the over-indulgent and lusty female. Poor, young, a majority of them unmarried and living in squalid quarters, these "hysterics" suffered great deprivation. Their repeated fainting spells and amenorrhoea, so it seems, were often subjected to "hysterization" when their main problem was probably nutritional. In one instance, even Cullen found it prudent to keep a hysteric woman in the "warmth and shelter of the house" for two additional weeks because of the cold weather prevailing in Edinburgh, a rare gesture in an establishment constantly overflowing with patients. ${ }^{68}$ Moreover, a few women

\footnotetext{
${ }^{66}$ See, for example,C. Smith-Rosenberg, 'The hysterical woman: sex roles and conflict in nineteenth-century America', Social Research, 1972, 39: 652-678; and P. Bart, 'Social structure and vocabularies of discomfort: what happened to female hysteria', J. Hlth soc. Behavior, 1968, 9: 188-193.

${ }^{67}$ Harold Merskey, The analysis of hysteria, London, Baillière Tindall, 1979, p. 243. For another comparative view of historical views about hysteria, see P. Chodoff, 'hysteria and women', Amer. J. Psych., 1982, 139: 545-551; and P. B. Bart and D. H. Scully, 'The politics of hysteria: the case of the wandering womb', in E. S. Gomberg and V. Frank (editors), Gender and disordered behaviour, New York, Brunner-Mazel, 1979, pp. 354-380.

${ }^{68}$ Case of Elizabeth Miller, in John Gregory, op. cit., note 35 above.
} 
admitted with symptoms suggestive of hysteria and amenorrhoea were actually pregnant. They expected that medical and physical measures instituted to correct their lack of menses would provoke an abortion. ${ }^{69}$

In conclusion, the evidence here presented from the Edinburgh Infirmary contradicts Foucault's notion that the poor had little concern for their bodily care and sexual functions. ${ }^{70}$ As the clinical histories amply demonstrate, patients suffering from hysteria demanded relief from their symptoms and were willing to put up with a number of medical treatments, from irritating salts to electric sparks, purgatives to blisters. Responding to their requests for help, hospital practitioners, in turn, validated the symptoms, made the expected diagnosis, and prescribed medicinal and physical measures traditionally judged to be useful in promoting recovery. Faced with a new clientèle drawn from the lower classes, eighteenth-century physicians reconstructed and redefined the boundaries of some traditional ailments such as hysteria. Personal reputation and their very status as professionals and educators depended on it. Whether this phenomenon was peculiar to Scotland, and to Edinburgh in particular, remains to be elucidated. In the meantime, one can certainly include "hysterization" within the broader medicalization process taking place in Europe towards the end of the eighteenth century.

${ }^{69}$ Other women had already aborted: "We are frequently deceived by women with child who, wishing to get rid of their burden, produce a miscarriage and attribute many complaints to a cessation of the menses, which they are cunning enough to say happened many a month before." Gregory, op. cit., note 15 above, p. 104. (See appendix 1.)

${ }^{70}$ Foucault, op. cit., note 1 above, p. 123. 


\title{
APPENDIX 1
}

\author{
HYSTERIA. A lecture by James Gregory delivered in 1788-89 \\ (MSS. Collection, National Library of Medicine, Bethesda, Maryland, USA)
}

This disease under which we have had several patients labouring is very disagreeable to the practitioner especially in an hospital where exercise, air and employment of mind are precluded though they may be reckoned among its most powerful remedies. For this reason I wish to take in as few hysteric patients as possible as I believe that more have been seized with this disease in the hospital than have been cured in it. I have known six seized with it in one night. It generally happens that a temporary relief is obtained by various remedies and as soon as that happens I send them out.

Tho the disease is not dangerous, it ought by no means to be passed over in silence as it is frequently very severe and many of the symptoms and forms it assumes are apt to deceive the young practitioner. As to the definition and description of it Dr. Cullen's are the best, but you must not expect to find the combination he finds in every case, for sometimes one symptom appears and sometimes another. Whenever the globus is present, I think the disease characterized, tho its absence by no means proves that hydrothorax is not present. I have sometimes known the sole symptoms of the disease to be a paralysis or loss of motion of every muscle of the body for some minutes; sometimes in the form of an intermittent.

The globus sometimes though rarely produces vomiting when it answers at the stomach, when in the throat it induces difficulty of deglutition: dysphagia hysterica, sometimes of the speech and at others asphyxia hysterica. The pulse is sometimes immoderately frequent. I have counted it at 180 and Dr. Whyte mentions having found it 220. Patients are at different times affected with weeping, laughing. They sometimes fall down motionless and at others have violent pains of the bladder and kidneys, and it has sometimes on this account been mistaken for calculous complaints.

I had a woman in the clinical ward labouring under hysteria who was affected with the most astonishing cough I have ever observed, continuing for two days without a second of intermission, and the conclusions are sometimes so astonishingly strong as to require the strait waistcoat. I believe I never knew hysteria produce an affection of the mind as epilepsy does though I think the frantic state of the mind may arrive at such a height as to produce similar effects. It has been supposed that hysteria may go to such a height as to promote epilepsy though I do not know that such has ever been the case. I had once a patient indeed in whom the two diseases completely marked were combined so that the patient would now perhaps be seized with an hysteric paroxysm and in a short time after with a fit of epilepsy. In the fit the distinction between the two diseases is rather difficult. The foaming is not always present in epilepsy and sometimes though not frequently accompanies hysteric paroxyms, but during the intervals and at the coming on of the disease it can readily be distinguished.

It has been a prevailing notion among physicians that hysteria was somehow associated with venereal appetite but though this may sometimes, yet it is not always the case. It is brought on by different passions as grief, anger, fear, and many women who might be supposed to make no scruple of owning it have on being questioned denied it.

Once circumstance in hysteria is to be particularly noticed, viz. that it depends on a particular predisposition proceeding from a certain mobility which is frequently connected with Debility. Baron [a patient] was not in this state, and the mobility I mention by no means depends upon it constantly - a peculiar concomitant irritability is likewise present; hence females are so subject to it. I would not, however, confine it entirely to them, though the instances of hysteric affections in the other sex are very few and in those cases which have been related I believe many mistakes have been made. I never saw but one instance of the kind myself, and that was in a young man who was affected with globus and he was of a very irritable habit, but I may safely say for one man 10,000 women are affected with the disease. 
Hysteria does not depend upon a general irritability on mobility alone, it seems in general to proceed from a particular irritability connected with the genital system. The general irritability is greater in infancy when no hysteria appears and it almost only occurs from the age of puberty to the cessation of the menses, and to this there are but few exceptions. I have seen women of 40 or 50 atacked with it and I knew a lady who was much affected with the disease in her younger days, attacked with strongly marked hysterical symptoms at the age of 66 . It frequently attends the sanguine temperament which is generally much connected with irritability. There is a remarkable connection too between it and the period of menstruation. I knew a lady who was affected with hysteria during the flowing of the menses from causes which at another time could produce no such effect, and it may be observed that the period of menstruation is one of usual and general irritability.

This peculiar irritability of the system productive of the disease may arise from innumerable causes, but the proximate cause may remain unknown to us as long as the nature of the nervous system sensations, and is so little understood. It seems much connected with a flaccidity of the simple solids and it is partly by its effects on these, partly by its action on the living principle that heat such as warm rooms has such a tendency to produce it.

This irritability is likewise connected with plethora as is shown by the temperament. It frequently attacks by its arising from the stoppage of evacuations and it is likewise connected with debility especially of the bowels and stomach, hence it accompanies dyspepsia. Custom seems to have a strong effect in resetting the disease as it has in asthma, epilepsy, intermittents. The effects of predisposition are in hysteria very remarkable - certain circumstances and causes which are indeed inevitable, often bring on the paroxysms in the predisposed which, if applied to 10,000 others not predisposed, would be productive of no effect. Such are the passions, external senses, sudden noise, certain smells either fragrant or otherwise, particular objects as cats or other animals, disagreeable sights particularly those of another person labouring under the disease and it frequently first commences that way.

The same tendency to imitate is observed in many other instances - as yawning, laughing, etc. As the muscles however employed in these last actions are in general subservient to the will, we can prevent the operation of that remarkable tendency towards them and I am sure much may be effected in that in hysteria. It is a maxim I inculcate very strongly to my patients, to use their utmost endeavours to prevent the coming on of fits. I have often known it succeed though my advice is by many not well received.

In others their predisposition is so strong that their endeavours are ineffectual. In some there is a peculiar pleasure that attends the coming on of the fit analogous I suppose to that we experience in yawning, and that they really encourage them and bring them on by reason of every possible effort, and in cases like these I should suppose every remedy must prove inefficacious. Fits are frequently brought on by theatrical performances. This happened in several instances during Mrs. Siddon's performing at Edinburgh. I knew one instance in Paris where death was the consequence of a violent fit occasioned by the representation of a tradgedy.

External heat is often likewise an exciting cause; hence are hysteric fits so frequently observed in crowded assemblies. Any great stoppage of an evacuation, any disorder of the stomach, renders the fits more violent. Hence it has been known to be brought on by full living and to come on constantly after a meal. I believe hysteric fits will never come on without some exciting cause; though our patients will frequently deny it, but this is no proof against it, for passions of the mind which they will not own and circustances so trifling that they are ashamed to acknowledge frequently induce it. I knew one instance in the clinical ward of a woman being seized with a violent fit on being denied a drink of water. As to the proximate cause, so little with respect to it is known that it is by no means applicable to practice.

Our indications of cure are 1st, in the intervals, to diminish extraordinary irritability and stop or moderate the fits. The first is answered by tonics such as the Peruvian Cortex from 3-3 $\frac{1}{2}$ gr 2-3 times a day. Steel, in doses of 15 grs or thereabouts, sometimes conjoined with bitters as gentian, columba, etc. Copper has been recommended. I have tried it in many respects but doubt much as to its good effects in hysteria. Exercise is of the greatest benefits and I believe has sometimes produced cures alone, and more especially when combined with the occupation of the mind. 


\section{Hysteria at the Edinburgh Infirmary}

We are often obliged to compel our patients to use it. I had an account of a lady who on the slightest threatening of a fit was immediately placed on horseback and obliged to ride pretty hard; this always prevented the further progress of the paroxysms and at length performed a cure. From hence it will appear of what service it must prove to undertake a journey especially on horseback for the cure of the disease.

With respect to moderating the fits, they are never attended with danger; at least I never saw them, so that we have generally nothing else to do but to prevent the patients from hurting themselves. The principal disadvantage that arises from them is that habit they induce, and to prevent this and stop the progress of the fits many medicines have been proposed, as foetids to the nose, pediluvium, dipping the hands in cold or warm water, dashing cold water on the face, and I have frequently known attended with success draughts with volatile alkali or ether, immediately before the fit and frequently to prevent its formation. I believe they possess more power then than at any other time.

Opium has likewise been given with the same intent by the mouth or by glyster, but they generally loose their effects in a little time. Camphor has been recommended and I have tried it without much success. With respect to my particular practice in these cases we had under our care, I ordered the pediluvium, the pil alvet with a view to bring on the menses, though I confess we ought to be cautious about administrating them. For we are frequently deceived by women with child who wishing to get rid of their burden produce a miscarriage and attribute many complaints to a cessation of the menses which they are cunning enough to say, happened many a month before.

How far this was the case with our patient I shall not say - but supposing a real amenorrhoea present, I know nothing so powerful in restoring the menses as the aloetic pills from the great irritability given the rectum. She was remarkable hard to work as a scruple had no effect. The anodyne castor, asa foetida, were given without any benefit. At the period of the menses, electricity and oil of Savin were employed to which I believe the root owes its virtues and I look upon it as the best mode of exhibiting it, but I am far from placing much trust in this or any other emmagogue. The only remedy which seemed to have any effect was the cold bath. Some of you saw the good effects of the draughts of ether and the fetid julep.

\section{APPENDIX 2: CASE OF HYSTERIA}

\section{Patient:
Notebook:
Location:
Age:
Sex:
Admitted:} Isabel Gray Clinical cases of Dr. Gregory in the Royal Infirmary of Edinburgh, taken by Nathan Thomas, 1785-86.

Location: $\quad$ MSS. Collection, University of Edinburgh 24

Admitted: 4 November 1785 (according to the General Register of Patients). Transferred to the teaching ward 6 Novenber, during James Gregory's three-month rotation as professor in charge (1 November 1785 to 31 January 1786)

\section{Diagnosis Hysteria (General Register lists her as suffering from dyspepsia)}

This young woman gave a history of premenstrual symptoms which included nausea, headaches, and oppression in the chest. These were followed by episodes of suffocation "creeping over the body" and convulsion considered typical of hysteria. Her complaints were chronic and in the patient's mind had a psychological cause: loss of her parents.

Before arriving at the teaching ward, Infirmary physicians pursued the traditional cleansing of stomach and gut through the administration of emetics and purgatives. This was followed by the prescription of a stimulating regimen consisting of pills with iron filings and a water extract of gentian root (infusion amarum) to enhance appetite. Both medications were considered tonics and their administration was designed to strengthen the patient's debilitated constitution.

Once under the care of James Gregory, the therapeutic attention shifted towards the control and prevention of hysteric fits which could be so disruptive. For this reason, Gregory prescribed a draught of sulphuric ether, and in spite of some difficulties in having the nurses administer the solution, was able to control the seizures. However, his additional orders of localized electrical sparks to the throat to alleviate the suffocating sensations of "globus" were unsuccessful. The 
same can be said of cold water baths. Opium had to be administered to settle some iatrogenically produced bowel cramps following the prescription of rhubarb pills (pilulae stomachicae), a moderate cathartic. The patient was promptly discharged after being in the hospital for only ten days, since she was temporarily without fits. Gregory listed her departure quite honestly as merely "relieved" - relieved of her main symptoms - while the clerks composing the General Register of Patients claimed that the patient had been "cured", no doubt to improve the overall hospital statistics, which had great public relations value.

6 November 1785. Is liable at the interval of a month and most commonly about the time of menstruation of which she commonly has little or no warning. She, however, before their commencement has a sense of oppression about the precordia, and some degree of nausea. She is suddenly seized with vertigo and falls down insensible, is convulsed in all limbs, and foams at the mouth. After continuing in this state for some time, she becomes insensible and does not return to her senses for a quarter of an hour or longer. She frequently complains of an headache attended with a throbbing of the temples, and a sense of knocking at her forehead. Has the sensation of a ball rising to her throat with a sense of suffocation and what she calls the creeping over her body. These symptoms are most urgent just before and after the fits. She is also troubled with tension and acidity of the stomach, and ruminates her food; appetite tolerable.

Tongue clean, pulse about 70 , feeble; belly costive, menses regular. These symptoms came on about two years ago, and she ascribes them to the loss of her parents. Has been in the hospital since the 12 [October?]. Since which she has been purged, vomited, and has been using chalybeats [iron preparations] and the infusion [of gentian root] without benefit. When threatened yesterday with a fit, she had a draught of ether and laudanum which put it off.

7 November. No fits today but frequent threatenings of them. Repeat iron pills and bitter infusion. If paroxysm should recur, promptly administer vitriolated ether draught. Common enema in the afternoon.

8 November. Had a strong fit yesterday preceded by globus, which last still continues but has produced no more fits. Did not get the draught as intended. Repeat previous medications. Apply electricity as sparks. Repeat draught as needed.

9 November. Had the sparks but not the shocks about the throat. Globus not removed at the time but almost gone now, she says. When a fit was beginning yesterday afternoon, she got the draught and the fit did not go on. Has had [the] threat [of fits] three times a day, took the draught first time and none of them [fits] went on. Omit electricity and ether. In the future wash [patient] with cold water.

10 November. No fits today or threatenings. Has used all her medicine except the pills. Omit the pills. Repeat the remaining [medication].

11 November. No more fits. Globus very troublesome; complains of general pains of her limbs. Skin cool. Pulse and countenance natural. Omit cold bathing. Repeat the remaining [medications].

12 November. No fits in 5 days. Still some slight remains of globus commonly in the throat, sometimes in the abdomen. Continue.

13 November. No more fits but much globus in the throat, inflation, pain, and borborygmi in the stomach and hypochondrium. Repeat draught with ether and vitriol. Stomach pills (rhubarb).

14 November. By mistake did not get the draught with ether as intended. Rhubarb pills operated thrice; still complains of gripes and borborygmi. Globus continuing and some nausea but no more fits. Ether draught as prescribed. Should have pill with 1 grain of opium at bedtime.

15 November. Continues easier in every way. Short, immediate relief from the draught. Goes out relieved.

Dr Gregory's commentary to the students: This was plainly a nervous hysteria complaint. She was attacked about the time her menses should appear every month. Her symptoms gave me a suspicion that epilepsy made a part of her disease but she had plainly some hysteric symptoms [such] as globus, etc. This disease may be truly called the protean form for every year I meet with it in a new shape. For this reason I take a great number of these patients in [so] that you see it in its different shapes. 